\title{
Nurse home visits during pregnancy and early childhood had positive effects on aspects of maternal life course 3 years later
}

Kitzman H, Olds DL, Sidora K, et al. Enduring effects of nurse home visitation on maternal life course. A 3-year follow-up of a randomized trial.JAMA 2000 Apr 19;283:1983-9.

QUESTION: Does a programme of nurse home visits during pregnancy and the first 2 years of the child's life continue to affect the life course of high risk mothers 3 years after the end of the programme?

\section{Design}

Randomised \{allocation concealed\}*, blinded (outcome assessors) controlled trial with follow up at 3 years after the programme ended.

\section{Setting}

An obstetrics clinic and county health department in Memphis, Tennessee, USA.

\section{Patients}

743 women (mean age 18 y, 97\% black) who were $<29$ weeks pregnant, had no previous live births, no chronic illnesses that might affect pregnancy outcome, and $\geqslant 2$ sociodemographic risk factors (unmarried, $<12$ y education, or unemployed). Follow up was $87 \%$.

\section{Intervention}

228 women received free transportation to prenatal appointments, an average of 7 home visits during pregnancy, 1 postpartum hospital visit, developmental screening for the child at ages 6,12 , and 24 months, and an average of 26 home visits until the child's second birthday (home visit group). Home visits focused on counselling and education about child care, health behaviour, and life planning. 515 women received only free transportation and developmental screening (control group).

\section{Main outcome measures}

Main outcomes included subsequent pregnancies, interval between first and second births, and months receiving welfare (Aid to Families with Dependent Children [AFDC] and food stamps). Secondary outcomes included mother's education and employment, living arrangements, partner's employment, use of Medicaid and a nutritional supplementation programme (WIC), and subsequent spontaneous and therapeutic abortions, still births, low birthweight infants, and neonatal care unit admissions.

\section{Main results}

Analysis was by intention to treat and adjusted for mother's psychological resources, household income, and neighbourhood poverty level. At 54 months after birth, women who received home visits had fewer subsequent pregnancies $(1.15 v 1.34, \mathrm{p}=0.03)$ than women in the control group, longer intervals between first and second births (30 $v 27 \mathrm{mo}, \mathrm{p}=0.004)$, and fewer months of using AFDC (33 $v 36, \mathrm{p}=0.01)$ and food stamps (42 v $45, \mathrm{p}=0.005)$. They were more likely to be living with a partner $(43 \%$ v 32\%, $\mathrm{p}=0.006)$, living with the child's father $(19 \% v 13 \%, \mathrm{p}=0.03)$, and have partners who had been employed for longer durations (35 $v 26 \mathrm{mo}$, $\mathrm{p}=0.04)$. The groups did not differ for maternal education or employment, use of Medicaid or nutritional supplementation programme, or subsequent spontaneous abortions, still births, or low birthweight infants; non-significant trends favouring the home visit group existed for lower rates of therapeutic abortions $(0.05 v$ $0.1, \mathrm{p}=0.07)$ and neonatal care unit admissions for subsequent births $(0.14 v 0.2, \mathrm{p}=0.09)$.

\section{Conclusion}

A programme of nurse home visits to high risk mothers during pregnancy and the first 2 years of the child's life had positive effects on their reproductive choices, family situation, and use of welfare 3 years after the end of the programme.

*Information provided by author.

\author{
Sources of funding: US \\ Department of Health \\ and Human Services, \\ Carnegie Corporation of \\ New York, and the Robert \\ Wood Johnson \\ Foundation. \\ For correspondence: \\ Dr D L Olds, University \\ of Colorado Health \\ Sciences Center, 1825 \\ Marion St, Suite 200 \\ Denver, CO 80218, USA. \\ $\mathrm{Fax}+13038645236$
}

\section{COMMENTARY}

In 1997, Kitzman et al published the initial results of this trial of home visits by nurses with disadvantaged, first time, young mothers in an urban, black population. ${ }^{1}$ This exemplary study replicated many of the health and social effects of a similar programme with a rural, white population, which proved continuing effects after 15 years. ${ }^{2}$ We now have the 5 year follow up of the women in Memphis and can recognise the same design strengths in randomisation, measurement, participation, follow up, and analysis.

The implications of these findings at a population level must be clearly stated. If we translated the results to a community of 100 similar families, over 5 years there would be, for example, 19 fewer pregnancies. Every first child would experience 4 more months of development before the demands of a sibling, and by age 5 would have lived 9 more months with an employed man in the household. There would be 11 more children living with 2 adults and 6 more living with their fathers and mothers. The government would pay 364 months less of AFDC and 347 months less of food stamps.

This critical information will inform programme planners and managers who design and advocate for programmes and will help nurses responsible for identifying women at risk in prenatal clinics and maternity wards. Public health nurses can take practice direction from this theory based intervention, which reinforces a client centred approach to encouraging women in planning and controlling their lives.

Why, however, was the effect on education and employment less than expected? Causal links between home visits and these outcomes are complex, with many intervening variables, such as the availability and nature of educational and employment opportunities. Such outcomes likely need interventions that include input from education, health, social service, and justice sectors.

The women in this trial had extremely low annual household incomes. In this context, the results give insight into individual factors that mitigate programme effects. Changes in reproductive health outcomes were concentrated among women with greater psychological resources, indicating that internal capacities are an important determinant of effects that appear closely linked to individual efficacy.

We cannot ignore the accumulated evidence that links nurse home visits with improvements in health and social outcomes in disadvantaged communities. We must now look at the values and resources that will determine whether this research is used for the good of communities.

Sarah Hayward, RN, MPH
Manager, SEARCH Program
Alberta Heritage Foundation for Medical Research
Edmonton, Alberta, Canada

1 Kitzman H, Olds DL, Henderson CR et al. Effect of prenatal and infancy home visitation by nurses on pregnancy outcomes, childhood injuries and repeated childbearing: a randomized, controlled trial. JAMA 1997;278:644-52.

2 Olds DL, Eckenrode J, Henderson CR, et al. Long-term effects of home visitation on maternal life course and child abuse and neglect. Fifteen year follow-up of a randomized trial. JAMA 1997;278:637-43. 